\title{
Increased release of von Willebrand factor antigen from endothelial cells by anti-DNA autoantibodies
}

\author{
Kar Neng Lai, Joseph C K Leung, Ka Bik Lai, Fernand M Lai, Kong Chiu Wong
}

\begin{abstract}
Objective-To determine whether antibodies to double stranded DNA (antidsDNA) have a pathogenic role in systemic lupus erythematosus (SLE). Methods-IgG was purified from 17 patients with SLE (median anti-dsDNA titre $1212 \mathrm{IU} / \mathrm{ml}$ ) and nine healthy controls (median titre $40 \mathrm{IU} / \mathrm{ml}$ ). Anti-dsDNA depleted polyclonal IgG (median antidsDNA titre $17 \mathrm{IU} / \mathrm{ml}$ ) was also prepared from sera of the 17 patients by affinity chromatography on a DNA cellulose column. Binding to antiendothelial cell antibodies (AECA) and expression of von Willebrand factor (VWF) antigen by cultured human umbilical vein endothelial cells (HUVECs) were studied by flow cytometry.
\end{abstract}

Results-The percentage of HUVECs binding to AECA or expressing VWF was greater for cells incubated with IgG from patients with SLE than for cells incubated with control IgG, though values did not reach statistical significance; nevertheless, HUVECs incubated with IgG from patients expressed a greater mean fluorescence intensity with AECA $(p=0.0001)$ and greater VWF expression $(p=0 \cdot 019)$. Both the fluorescence intensity and percentage of HUVECs binding to AECA or expressing VWF were significantly greater in HUVEC incubated with IgG containing anti-dsDNA than in those incubated with anti-dsDNA depleted IgG. The concentration of VWF in the supernatant was significantly increased in HUVECs incubated with IgG containing antidsDNA compared with control IgG or anti-dsDNA depleted IgG. Pretreatment of HUVECs with native DNA before incubation with IgG from lupus patients did not increase binding to AECA, or expression or release of VWF.

Conclusions-Our study provides in vitro evidence that antibodies to DNA have a pathogenic role in the induction of inflammatory injury of the vascular endothelium in SLE.

(Ann Rheum Dis 1996; 55: 57-62)

The pathogenic mechanism of vasculitis and nephritis in systemic lupus erythematosus (SLE) remains a subject of debate. Human and animal studies in $B / W$ mice show the presence of anti-double stranded DNA antibodies (antidsDNA), DNA and complement in kidney eluates, suggesting a possible pathogenic role for DNA-anti-DNA immune complexes. ${ }^{12}$ In addition, a correlation has been reported between pretreatment anti-dsDNA titre in serum and severity of the disease, particularly in the case of glomerulonephritis. ${ }^{34}$ Other evidence for a direct pathogenic function of antidsDNA is not strong.

Plasma concentrations of von Willebrand factor (VWF) antigen are increased in patients with SLE and other vasculitic lesions, and are considered to be an indicator of endothelial cell damage. ${ }^{56}$ There is, however, little information to suggest that antibodies to dsDNA release these endothelial products.

In this study, we examined the expression and release of VWF from, and the binding of antiendothelial cell antibodies (AECA) to, cultured human umbilical vein endothelial cells (HUVECs) in response to IgG containing anti-dsDNA and IgG depleted of anti-dsDNA from patients with SLE, to determine any direct pathogenic effect of anti-dsDNA on endothelial injury.

\section{Materials and methods}

IMMUNOGLOBULIN PREPARATION

Sera were obtained from 17 randomly selected patients with SLE (12 female; mean age 25 (SEM 4) years) before they received immunosuppressive treatment, and from nine healthy controls (eight female; mean age 28 (4) years). The patients with SLE fulfilled the criteria of the American Rheumatism Association ${ }^{7}$ and none of them had a clinical history of thrombosis.

Purified IgG preparations were prepared by affinity chromatography with protein-G sepharose (Pharmacia LKB, Uppsala, Sweden) and their purity ascertained by sodium dodecyl sulphate-polyacrylamide gel electrophoresis. Endotoxin was not detected in the IgG preparations by Limulus amoebocyte lysate test as previously described. ${ }^{8}$ The possible cytotoxicity caused by these autoantibodies was studied by chromium release from ${ }^{51} \mathrm{Cr}$ labelled HUVECs incubated with different IgG preparations. The IgG preparations were adjusted to $10 \mathrm{mg} / \mathrm{ml}$ and the anti-dsDNA titre was determined by an enzyme linked immunosorbent assay (ELISA) (NovoPath antidsDNA kit, Biorad, Hercules, CA, USA). All IgG preparations were tested for anticardiolipin antibody, tumour necrosis factor $\alpha$ $(\mathrm{TNF} \alpha$ ), and interleukin $1 \beta$ (IL-1 $\beta$ ). IgG depleted of anti-dsDNA were prepared by passing $20 \mathrm{mg}$ of IgG preparation through a native DNA-cellulose column (Pharmacia) 
and the flow through was collected, dialysed, and concentrated to $10 \mathrm{mg} / \mathrm{ml}$. Complete removal of anti-dsDNA was confirmed by the NovoPath anti-dsDNA ELISA. The IgG and anti-dsDNA depleted IgG preparations were stored at $-70^{\circ} \mathrm{C}$ until required for use.

IMMUNOASSAYS FOR CYTOKINES IN IgG PREPARATIONS

'Sandwich' ELISAs were used to measure TNF $\alpha$ (Genzyme, Boston, MA, USA) and IL-1 $\beta$ ( $R \&$ D System) in the IgG preparations. In all the assays, two separate monoclonal or polyclonal antibodies were used, each recognising a separate epitope of the respective molecule. Results were determined from a standard curve derived from the optical densities of the different dilutions of the standard samples. The lower limits of sensitivity for the assays are $0.03 \mathrm{pg} / \mathrm{ml}$ (IL-1 $\beta$ ) and $5 \mathrm{pg} / \mathrm{ml}(\mathrm{TNF} \alpha)$. All samples were assayed at the same time to avoid between batch variation. Intra-assay coefficient of variation was less than $5 \%$ for all assays.

\section{ISOLATION AND CULTURE OF ENDOTHELIAI}

CELIS

HUVECs were isolated according to the method of Jaffe et $a l^{9}$ and cultured on a $1 \%$ gelatin coated tissue culture flask (Falcon, Becton-Dickinson, Mountain View, CA, USA) with M199 culture medium containing $20 \%$ heat inactivated fetal bovine serum, $100 \mathrm{U} / \mathrm{ml}$ penicillin and streptomycin (Gibco, Chargrin Falls, NY, USA), $0.25 \mathrm{mg} / \mathrm{ml}$ heparin, and $20 \mu \mathrm{g} / \mathrm{ml}$ endothelial cell growth supplement (Sigma, St Louis, MO, USA). Endothelial cell phenotype was confirmed by a typical cobblestone morphology, and the presence of VWF by immunofluorescence staining using monoclonal antihuman VWF (Dako, Copenhagen, Denmark).

\section{CYTOTOXICITY ASSAY}

Second to third passage HUVECs were plated out into 24 well culture plates. Chromium-51 labelling was performed by incubating $1 \mu \mathrm{Ci}$ of chromium-51 ( $1 \mathrm{mCi} / \mathrm{ml}$; Amersham, UK) in $300 \mu$ l culture medium for 24 hours at $37^{\circ} \mathrm{C}$. After three washes with phosphate buffered saline (PBS) to remove excess radiolabel, the cells were incubated in triplicate with 0.5 $\mathrm{mg} / \mathrm{ml} \mathrm{IgG} \mathrm{in} \mathrm{medium,} \mathrm{M199}$, or $100 \mathrm{pg} / \mathrm{ml}$ TNF $\alpha$ for 16 hours at $37^{\circ} \mathrm{C}$. The plates were centrifuged at $800 \mathrm{rpm}$ for five minutes, the culture supernatant removed, and the released radioactivity measured by gammacounter. The results were expressed as percentage specific release $=(\mathrm{cpm}$ experimental - cpm spontaneous)/(cpm total - cpm spontaneous) $\times 100 \%$, where total release indicated the radioactivity collected after $100 \mu \mathrm{l}$ of $2 \mathrm{~mol} / 1 \mathrm{NaOH}$ was added, and spontaneous release was the radioactivity in the supernatant from cell cultures in medium alone.
Table 1 Preliminary study for determination of optimal concentration of IgG from lupus patients on expression and release of VWF from cultured HUVECs

\begin{tabular}{lll}
\hline $\begin{array}{l}\text { IgG concentration } \\
(\mathrm{mg} / \mathrm{ml})\end{array}$ & $\begin{array}{l}\text { VWF expression } \\
\text { (mean fluorescence } \\
\text { channel number) }\end{array}$ & $\begin{array}{l}\text { VWF in supernate } \\
(\mathrm{mIU} / \mathrm{ml})\end{array}$ \\
\hline 0 & 450 & $3 \cdot 352$ \\
$0 \cdot 125$ & 463 & $4 \cdot 176$ \\
$0 \cdot 25$ & 478 & $5 \cdot 165$ \\
0.5 & 510 & $6 \cdot 153$ \\
1 & 523 & $6 \cdot 562$ \\
2 & 533 & $7 \cdot 013$ \\
4 & 540 & $7 \cdot 152$ \\
\hline
\end{tabular}

Values represent mean of IgG preparations from three lupus patients.

FLOW CYTOMETRIC ANALYSIS OF VWF EXPRESSED ON AND AECA BOUND TO HUVEC Second to third passage HUVECs were plated out into 24 well gelatin coated tissue culture plates (Costar, Cambridge, MA, USA) at a concentration of $2.5 \times 10^{5}$ cells per well for 24 hours before the experiment. The confluent cells were then incubated at $37^{\circ} \mathrm{C}$ in triplicate with $0.5 \mathrm{mg} / \mathrm{ml} \mathrm{IgG}, \mathrm{M} 199$, or TNF $\alpha$ (Boehringer, Mannheim, Germany) at a final concentration of $1000 \mathrm{pg} / \mathrm{ml}$ in complete culture medium for 16 hours; the optimal concentration of IgG was determined by preliminary studies of the expression and release of VWF by cultured HUVECs (table 1), and the HUVECs were incubated for 16 hours to achieve a near-maximal release of $\mathrm{VWF}$ (table 2). After incubation, supernatant samples were collected and stored at $-70^{\circ} \mathrm{C}$ until required for VWF assay. The cells were washed with PBS, harvested at room temperature with $0.5 \mathrm{mmol} / 1 \mathrm{EDTA}$ in PBS, and transferred into $12 \times 75 \mathrm{~mm}$ tubes. The cell suspensions were divided into two portions: one was stained for binding to human IgG using affinity purified fluorescein isothiocyanate (FITC) conjugated goat anti-human IgG F $\left(\mathrm{ab}^{\prime}\right)_{2}$ preparation (Tago, Camarillo, CA, USA); the other was stained for VWF expression using monoclonal antihuman VWF (Dako) as primary antibody and affinity purified FITC conjugated $\mathrm{F}\left(\mathrm{ab}^{\prime}\right)_{2}$ fragment of goat antimouse immunoglobulins as secondary antibody (Dako). Background control staining of the HUVECs was achieved by reaction with either preimmune FITC conjugated goat IgG $\mathbf{F}\left(\mathrm{ab}^{\prime}\right)_{2}$ (Tago) or isotype matched mouse IgG (Dako). The stained cells were analysed using a FACScan analyser (Becton-Dickinson) and a technique adopted from Westphal et al. ${ }^{10} \mathrm{~A}$ minimum of 5000 unfixed cells for each sample was analysed. Fluorescence intensity in each

Table 2 Kinetic study of soluble VWF release of VWF ( $\mathrm{mIU} / \mathrm{ml}$ ) from HUVECs incubated with $0.5 \mathrm{mg} / \mathrm{ml} \mathrm{IgG}$

\begin{tabular}{llll}
$\begin{array}{l}\text { Duration of } \\
\text { incubation } \\
\text { (nours) }\end{array}$ & $\begin{array}{l}\text { Control } \\
\text { IgG }\end{array}$ & $\begin{array}{l}\text { Anti-dsDNA } \\
\text { depleted } \\
\text { IgG }\end{array}$ & $\begin{array}{l}\text { Anti-dsDNA } \\
\text { IgG }\end{array}$ \\
\hline 0 & 3.54 & 3.81 & 3.69 \\
2 & 3.84 & 4.26 & 4.79 \\
4 & 3.92 & 4.53 & 4.96 \\
6 & 3.96 & 4.62 & 5.26 \\
8 & 4.05 & 4.86 & 5.48 \\
16 & 4.20 & 5.05 & 6.55 \\
24 & 4.22 & 5.21 & 7.14 \\
48 & 3.98 & 5.08 & 6.98 \\
\hline
\end{tabular}

Values represent mean of IgG preparations from three lupus patients and three controls. 
experiment was evaluated by comparing the mean fluorescence channels without subtraction of control staining. The percentage of HUVECs with fluorescence intensity greater than the background from isotypic control antibodies was also determined. All staining for a single molecule was done in a single batch to avoid between batch variation.

ELISA FOR MEASURING VWF IN SUPERNATE Supernatant concentrations of VWF in HUVECs cultured with IgG, medium, or TNF were assayed using a modified technique of Lindsey et al. ${ }^{11}$ ELISA plates were coated with monoclonal antibodies against VWF (Dako) in $0.05 \mathrm{~mol} / \mathrm{l}$ carbonate buffer, $\mathrm{pH} 9.6$, overnight at room temperature. After washing with PBS containing $0.05 \%$ Tween 20 , the plates were blocked for non-specific binding with $3 \%$ bovine serum albumin in PBS for one hour. After washing, the culture supernate and VWF standards (Immuno, Sevenoaks, Kent, UK) were added to the wells and further incubated for two hours. The plates were washed three times with PBS/Tween and then incubated with a peroxidase labelled polyclonal antibody against human VWF (Dako) for one hour. After a further three washes, the plates were incubated with $0.05 \%$ orthophenylenediamine hydrochloride and $0.01 \%$ hydrogen peroxide and the resulting colour reaction measured at $492 \mathrm{~nm}$ using an ELISA reader.

PREINCUBATION OF HUVEC WITH DNA

In order to determine whether immune complexes formed by anti-dsDNA with DNA on the surface of HUVECs were necessary for endothelial activation, all experiments were repeated in cultured HUVECs pretreated with calf thymus native DNA (Sigma) at a concentration of $50 \mu \mathrm{g} / \mathrm{ml}$ for one hour before further incubation with IgG preparation.

STATISTICS

Because the distribution of the data appeared not to be normal, group results were expressed as median and range unless stated otherwise, and non-parametric tests for significance were performed. The data between the IgG preparations from patients with SLE and healthy controls were tested using the Wilcoxon rank sum test, and data between IgG containing anti-dsDNA and anti-dsDNA depleted IgG were analysed with the signed rank test. Relationships between the expression and release of VWF, AECA, or anti-dsDNA titre were examined by Spearman Rank Correlation. Statistical significance was assigned at $\mathrm{p}<0.05$.

\section{Results}

The anti-dsDNA titres of the IgG preparations from lupus patients (median $1212 \mathrm{IU} / \mathrm{ml}$, range 377-9662) were significantly greater than those of the healthy controls (median 40 $\mathrm{IU} / \mathrm{ml}$, range $23-52 ; \mathrm{p}<0.0001)$. After passage through a native DNA-cellulose column, the anti-dsDNA titres of the flow through IgG (anti-dsDNA depleted IgG) decreased to negligible values (median $17 \mathrm{IU} / \mathrm{ml}$, range $1-64 ; \mathrm{p}<0.0001)$ compared with the original IgG preparations. Anticardiolipin antibody, $\mathrm{TNF} \alpha$, and IL-1 $\beta$ were not detected in these IgG preparations. No cytotoxicity was detected in HUVECs exposed to IgG preparations. The average release of chromium-51 from HUVECs incubated with IgG preparations $(4.8 \%)$ was similar to that observed in HUVECs incubated with culture medium $(5 \cdot 0 \%)$. However, release of chromium-51 from HUVECs incubated with TNF $\alpha$ (1000 $\mathrm{pg} / \mathrm{ml}$ ) was $15 \%$, suggesting cytotoxicity induced by this dose of TNF $\alpha$.

The AECA were determined indirectly as the binding of IgG to the HUVECs: there was an apparent increase in the percentage of HUVECs binding to IgG from patients with SLE compared with IgG from healthy controls, though the difference failed to reach statistical significance (fig 1A). The concentration of
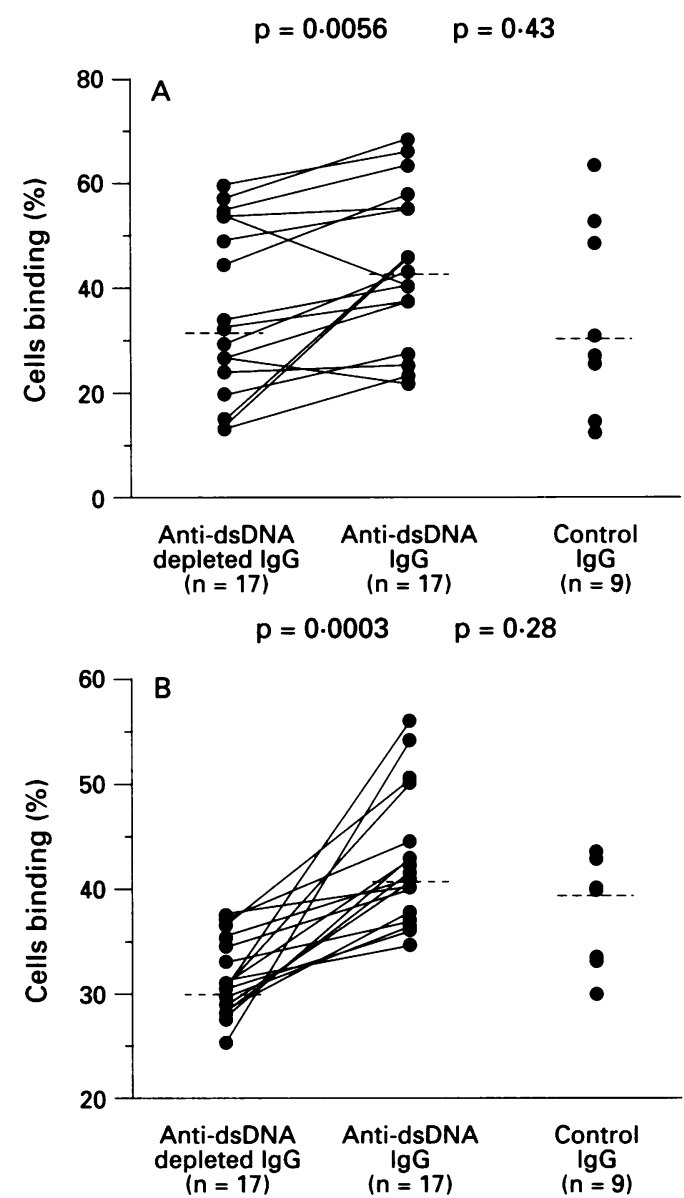

Figure 1 A: Percentage of human umbilical vein endothelial cells (HUVECs) binding to antiendothelial cell antibodies after incubation with IgG containing antidsDNA (anti-dsDNA IgG), anti-dsDNA depleted IgG, or control IgG. Horizontal bar represents median value. Mean (SD) values of five experiments incubated with medium and tumour necrosis factor $\alpha(T N F \alpha) 1000 \mathrm{pg} / \mathrm{ml}$ were $10 \cdot 12(3 \cdot 1) \%$ and $61 \cdot 4(10 \cdot 8) \%$, respectively. Patients with SLE and healthy controls compared using the Wilcoxon rank sum test; anti-dsDNA IgG and antidsDNA depleted groups compared by signed rank test. $B$ : Percentage of HUVECs expressing von Willebrand factor after incubation with different IgGs. Horizontal bar represents median value. Mean (SD) values of five experiments incubated with medium and TNF $\alpha$ were 28.2 $(2.9) \%$ and $55.4(6.4) \%$, respectively. 
AECA measured by the fluorescence intensity on HUVECs was significantly increased in IgG from patients with SLE compared with IgG from healthy controls (fig $2 \mathrm{~A}$ ).

The expression of VWF on cultured HUVECs in response to stimulation by different IgG preparations was determined as binding to antihuman VWF antibody measured by flow cytometry. Again, there was an apparent increase in the percentage of HUVECs expressing VWF when incubated with IgG from patients compared with control IgG, but the difference failed to reach statistical significance (fig 1B). As observed in AECA, the concentration of VWF measured by fluorescence intensity on HUVECs was significantly increased in HUVECs incubated with IgG from lupus patients compared with those incubated with control lgG (fig 2B).

To validate the selective effect of antidsDNA on expression of VWF by HUVECs, IgG containing anti-dsDNA and anti-dsDNA depleted-IgG were prepared from the 17 lupus
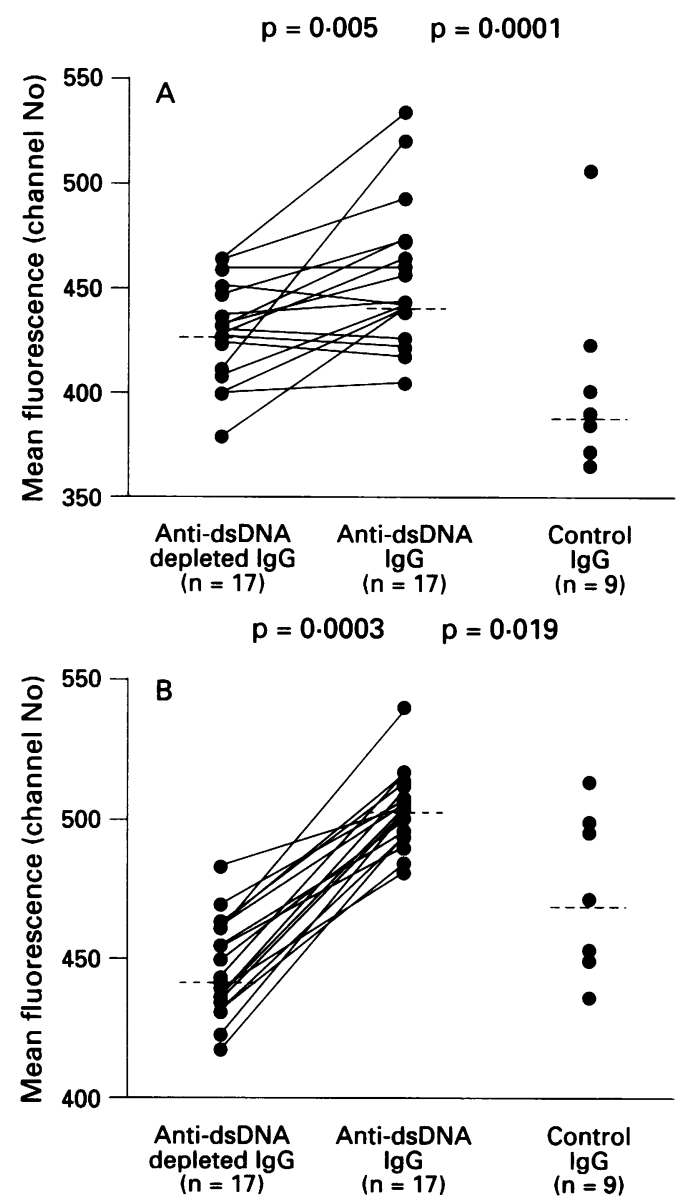

Figure 2 A: Fluorescence intensity of human umbilical vein endothelial cells (HUVECs) binding to antiendothelial cell antibodies after incubation with IgG containing antidsDNA (anti-dsDNA IgG), anti-dsDNA depleted IgG, or control IgG. Horizontal bar represents median value. Mean (SD) values of five experiments incubated with medium and tumour necrosis factor $\alpha(T N F \alpha)$ were 357.6 (29.3) and $535.9(43.8)$ respectively. Patients with SLE and healthy controls compared using the Wilcoxon rank sum test; IgG containing anti-dsDNA and anti-dsDNA depleted IgG groups compared by signed rank test. $B$ : Fluorescence intensity of HUVECs expressing von Willebrand factor after incubation with different IgGs. Horizontal bar represents median value. Mean (SD) values of five experiments incubated with medium and TNF $\alpha$ were $424 \cdot 2(35 \cdot 9)$ and $541.4(43 \cdot 5) \%$, respectively. patients by affinity chromatography. AECA was significantly reduced in anti-dsDNA depleted-IgG compared with IgG containing anti-dsDNA from the same patient, as shown by the lower percentage and lower fluorescence intensity of HUVECs binding to AECA (figs 1,2). Similarly, VWF expression was significantly reduced on HUVECs incubated with anti-dsDNA depleted IgG compared with HUVECs incubated with IgG containing antidsDNA from the same patient (figs 1, 2). Except for fluorescence intensity of binding to AECA ( $p=0.0165)$, HUVECs incubated with anti-dsDNA depleted IgG showed no increase in percentage of binding to AECA or expression of VWF compared with those incubated with control IgG. The supernatant concentration of VWF was significantly increased in HUVECs incubated with IgG containing anti-dsDNA compared with control IgG or anti-dsDNA depleted IgG ( $p=0.009$ and 0.0003 , respectively) (fig 3 ). Pretreating HUVECs with native DNA did not result in an additive effect of binding to AECA or expression and release of VWF (data not shown).

After incubation with IgG containing antidsDNA from patients with SLE, the percentage of HUVECs binding to AECA correlated significantly with the fluorescence intensity of AECA binding to HUVECs $\left(r_{\mathrm{s}}=0.53\right.$, $\mathrm{p}=0.027)$. Similarly, the percentage of HUVECs expressing VWF correlated significantly with the fluorescence intensity of VWF expression on HUVECs $\left(r_{\mathrm{s}}=0.79\right.$, $\mathrm{p}=0.0015)$. The fluorescence intensity of VWF expression on HUVECs following incubation with IgG containing anti-dsDNA correlated with the supernatant concentration of VWF $\left(r_{\mathrm{s}}=0.50, \mathrm{p}=0.044\right)$. There was no correlation between the anti-dsDNA titres and binding to AECA, or expression or release of VWF by HUVECs. No significant correlation was demonstrated between AECA levels and

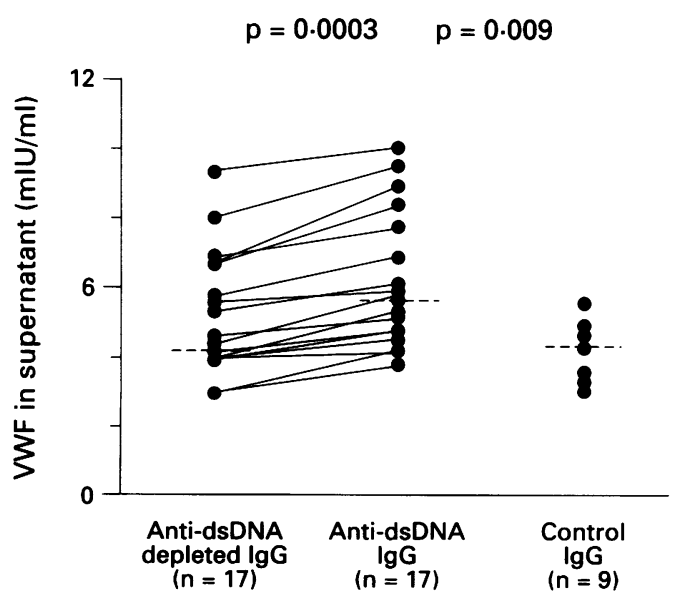

Figure 3 Supernatant concentrations of von Willebrand factor in human umbilical vein endothelial cells after incubation with IgG containing anti-dsDNA (anti-dsDNA IgG), anti-dsDNA depleted IgG, or control IgG. Horizontal bar represents median value. Mean (SD) values of five experiments incubated with medium and tumour necrosis factor $\alpha$ were $2 \cdot 1(1 \cdot 5) \%$ and $13 \cdot 2$ (4.1)\%, respectively. Patients with SLE and healthy controls compared using the Wilcoxon rank sum test; IgG containing anti-dsDNA and anti-dsDNA depleted groups compared by signed rank test. 
expression or release of VWF on HUVECs incubated with $\mathrm{IgG}$ from lupus patients.

\section{Discussion}

Circulating autoantibodies present in SLE patients, especially those against native double stranded DNA, have been shown to serve as an underlying substratum for the disease manifestation. A pathogenic role for anti-dsDNA of IgG isotype was indirectly established by the correlation of serum antibody titres with disease activity in some patients and the demonstration of DNA-anti-DNA immune complex deposition at sites of tissue damage such as kidney..$^{1-4}$ However, it is now becoming clear that anti-DNA antibodies are not always nephritogenic: ${ }^{12}$ in NZB/NZW mice, administration of syngeneic anti-DNA monoclonal antibody often suppresses the development of murine lupus nephritis. ${ }^{13}$ In addition, most patients, even those with active SLE, may not have free circulating DNA or DNA-anti-DNA complexes in the blood or eluates from the affected kidney. ${ }^{14}{ }^{15}$ Thus it remains questionable whether anti-dsDNA merely represent epiphenomena or have a direct pathogenic role.

Preliminary data in support of a direct pathogenic role for anti-dsDNA are few, but most intriguing. Sera from patients with SLE increased endothelial cell adherence, aggregation, and superoxide generation by neutrophils, ${ }^{16}$ and increased major histocompatibility complex class I antigen expression on cultured HUVECs. ${ }^{17}$ IgG from thrombosis susceptible patients with SLE stimulated the release of VWF from endothelial cells. ${ }^{11}$ Anti-dsDNA altered the mitogenic responses of mononuclear cells ${ }^{18}$ and exerted a cytotoxic effect on cultured rat mesangial cells. ${ }^{19}$ Binding of IgG in sera from lupus patients to endothelium initiated complement activation that may lead to vascular injury. ${ }^{20}$ In the present study, we have examined the effect of anti-dsDNA on the expression and release of VWF by HUVECs. Increased plasma concentrations of VWF are well recognised features of patients with vasculitis and autoimmune disorders, and have been taken to indicate the occurrence of in vivo endothelial cell damage. ${ }^{56}$ Lindsey et $a l^{11}$ reported that IgG from thrombosis susceptible patients with SLE stimulated the release of VWF from endothelial cells, and provided evidence that IgG isolated from patients with SLE was capable of acting as an agonist for VWF release. In this study, we purified IgG free of complement or cytokine that could release VWF from HUVECs. ${ }^{21}{ }^{22}$ Compared with IgG from healthy controls, the concentrations of AECA present in the IgG prepared from patients with SLE (measured by FACScan) were increased as determined by fluorescence intensity of HUVEC binding to IgG. Similarly, there was an increase in VWF expression on HUVECs incubated with IgG prepared from patients with SLE. The percentage of HUVECs binding to AECA or expressing VWF when incubated with IgG from SLE patients failed to reach statistical significance, probably because of the small number of controls. It may be argued that the effect of IgG from patients with SLE on HUVECs may represent the difference in a property of IgG from the individual patient or control, rather than a specific effect of anti-dsDNA. We approached this issue by preparing IgG containing anti-dsDNA and antidsDNA depleted IgG from the same patient, and used the latter as control for IgG containing anti-dsDNA. Instead of testing antidsDNA eluted from the DNA-cellulose column, we used IgG containing anti-dsDNA for comparison with anti-dsDNA depleted IgG, as the recovery of anti-DNA activity and loaded IgG in the eluate was often less than $40 \%$. ${ }^{23}$ Similarly, we failed to recover more than $35 \%$ of anti-DNA activity and loaded IgG, raising the possibility that the eluted antidsDNA were of low affinity. The anti-dsDNA titres of the anti-dsDNA depleted IgG were comparable to those of healthy controls. Our data demonstrated significantly greater AECA concentrations in IgG containing anti-dsDNA compared with anti-dsDNA depleted IgG. There was also increased expression of VWF on HUVECs incubated with IgG containing anti-dsDNA compared with those incubated with anti-dsDNA depleted IgG prepared from the same patient. These data indicate strongly that the effect of anti-dsDNA on the HUVEC is highly specific. The flow cytometry results relating to VWF were confirmed by the increased supernatant concentration of VWF in HUVECs incubated with IgG containing anti-dsDNA. AECA is considered to be a potential marker for nephritis and vasculitis in SLE, ${ }^{24}$ whereas VWF is a large adhesive glycoprotein that has an important role in the interaction of platelets and the blood vessel wall and is released after in vivo endothelial cell damage. $^{2125}$ Hence, our data provide additional evidence that anti-dsDNA directly stimulates endothelial cells and has a pathogenic role in the development of vasculitis in SLE. The direct stimulatory effect of antidsDNA on endothelium may have important pathological significance, as the release of VWF approximates $50 \%$ of the effect of TNF $\alpha$ at a concentration of $1000 \mathrm{pg} / \mathrm{ml}$. We confirmed the absence of correlation between antidsDNA titre, AECA concentrations, and expression or release of $\mathrm{VWF}^{1121}$ that may suggest a different pathogenic role of antidsDNA and AECA.

Previous studies suggested that the binding of anti-dsDNA to endothelial cells was mediated through DNA, which formed a bridge between the immunoglobulin and the DNA binding protein in the plasma membrane. ${ }^{26}{ }^{27}$ However, more recently Tsai et al ${ }^{19}$ reported direct binding of IgG containing antidsDNA to cell membrane of rat mesangial cells. Shibata et $a l^{28}$ have demonstrated that circulating anti-dsDNA can cross react with vascular heparan sulphate glycosaminoglycans, suggesting that at least a percentage of these autoreactive antibodies may be directed against epitopes in heparan sulphate that are conformationally related to those found in DNA. In 
this study, we have demonstrated no additive effect of expression of adhesion molecules in HUVECs pretreated with native DNA. These findings tend to suggest that anti-dsDNA can bind directly to the plasma membrane of HUVECs, perhaps via heparan sulphate glycosaminoglycans, without bridging through the DNA binding protein. The exact mechanism for VWF release by anti-dsDNA is not certain, and we have shown that direct cytotoxicity is unlikely to play a significant part. Complement dependent effects of AECA in VWF release did not operate in our in vitro studies, as the IgG preparations were free of complement.

It should be emphasised that our studies were performed with endothelial cells from umbilical vein. The recent rediscovery of heterogeneity in human aortic endothelium and variant endothelial cell populations ${ }^{29} 30$ raises the possibility that our observed effect of anti-dsDNA may not be completely identical in these endothelial cells. Further studies of endothelial cells with different phenotypes are required. In conclusion, our study provides preliminary evidence that anti-dsDNA has a direct pathogenic role in the development of vasculitis in SLE.

This study was supported by the Research Grant Committee (Hong Kong) (grant No CUHK 201/94M). The authors wish to thank staff of the Department of Obstetrics and Gynaecology, Prince of Wales Hospital for helping to collect the endothelia cells.

1 Koffler D, Shur P H, Kunkel H G. Immunologic studies concerning the nephritis of SLE. $\mathcal{f}$ Exp Med 1967; 126: 607-31.

2 Isenberg D A, Ehrenstein M R, Longhurst C, Kalsi J K. The origin, sequence, structure, and consequences of developing anti-DNA antibodies. Arthritis Rheum 1994 37: $169-80$.

3 Winfield J B, Faiferman I, Koffler D. Avidity of anti-DNA antibodies in serum and IgG glomerular eluates from patients with systemic lupus erythematosus: association patients with systemic lupus erythematosus: association
of high avidity anti-native DNA antibody with glomeruloof high avidity anti-native DNA antibody

4 Fournie G J. Circulating DNA and lupus nephritis. Kidney Int 1988; 33: 487-97.

5 Pearson J D. Markers of endothelial perturbation and damage. Br F Rheumatol 1994; 32: 651-2.

6 Blann A D. von Willebrand factor as a marker of injury to the endothelium in inflammatory vascular disease. f Rheumatol 1993; 20: 1469-71.

7 Tan E M, Cohen A S, Fries J F, et al. The 1982 revised criteria for the classification of systemic lupus erythematosus. Arthritis Rheum 1982; 25: 1271-7.

8 Lai K N, Leung J C K, Rifkin I, Lockwood C M. Effect of anti-neutrophil cytoplasm autoantibodies on the of anti-neutrophil cytoplasm autoantibodies on the intracellular calcium concentrat

9 Jaffe E A, Nachman E L, Becker C G, Minick C R. Culture of human endothelial cells derived from umbilical veins. Identification by morphologic and immunologic criteria. f Clin Invest 1973; 52: 1745-56.

10 Westphal J R, Boerbooms A M, Schalkwijk C J M, et al. Anti-endothelial cell antibodies in sera of patients with autoimmune diseases: comparison between ELISA and FACS analysis. Clin Exp Immunol 1994; 96: 444-9.

11 Lindsey N J, Dawson R A, Henderson F J, Greaves M Hughes P. Stimulation of von Willebrand factor antigen release by immunoglobulin from thrombosis prone patients with systemic lupus erythematosus and antipatients with systemic lupus erythematosus and anti-
phospholipid syndrome. $B r \quad \mathcal{F}$ heumatol 1993; 32: 123-6.

12 Steinberg A D, Smolen J S, Sakane T, et al. Immune regulatory abnormalities in systemic lupus erythematosus. In: Cummings N B, Michael A F, Wilson C B, eds. Immune mechanisms in renal diseases. New York: Plenum, $1982 ; 529$.

13 Hahn B H, Ebling F M. Suppression of NZB/NZW murine nephritis by administration of syngeneic monoclonal antibody to DNA: possible role of anti-idiotypic antibodies. F Clin Invest 1983; 71: 1728-36.

14 Izui S, Lambert $P$ H, Miescher P A. Failure to detect circulating DNA-anti-DNA complexes by four radioimmunological methods in patients with systemic lupus immunological methods in patients with systemic lupus.

15 Eilat D. Cross-reactions of anti-DNA antibodies and the central dogma of lupus nephritis. Immunol Today 1985; 6: central $123-7$.

16 Hashimoto $Y$, Ziff $M$, Hurd E R. Increased endothelial cell adherence, aggregation, and superoxide generation by neutrophils incubated in systemic lupus erythematosus and Felty's syndrome sera. Arthritis Rheum 1982; 25: 1409-18.

17 Yap H K, Ng S C, Lee B, et al. Modulation of MHC expression on human endothelial cells by sera from patients with systemic lupus erythematosus. Clin Immunol Immunopathol 1993; 68: 321-6.

18 Yu L, Chang K L, Chiu C C, Chiang B N, Han S H, Wang $S$. Alteration of mitogenic responses of mono-
nuclear cells by anti-ds DNA antibodies resembling nuclear cells by anti-ds DNA antibodies resembling immune disorders in patients with systemic lupus

19 Tsai C Y, Wu T, Sun K, Liao T, Lin W, Yu C. Polyclonal IgG anti-dsDNA antibodies exert cytotoxic effect on cultured rat mesangial cells by binding to cell membrane and augmenting apoptosis. Scand $\mathcal{f}$ Rheumatol 1993; 22: 162-71

20 Cines D B, Lyss A P, Reeber M, Bina M, DeHoratius R J. Presence of complement-fixing anti-endothelial cell antibodies in systemic lupus erythematosus. $\mathcal{F}$ Clin Invest 1984; 73: 611-25.

21 Paleolog E M, Crossman D C, McVey J H, Pearson J D. Differential regulation by cytokines of constitutive and stimulated secretion of von Willebrand factor from endothelial cells. Blood 1990; 75: 688-95.

22 Giddings J C, Shall L. Enhanced release of von Willebrand factor by human endothelial cells in culture in the presence of phorbol myristate acetate and interleukin-1. Thromb Res 1987; 47: 259-67.

23 Suenage R, Evans M, Hatfield M, Abdou N I. Study of antiDNA antibodies prepared by DNA-cellulose or Cibacron blue chromatography. F Immunol Methods 1986; 93: 131-40.

24 D'Cruz D P, Houssiau F A, Ramirez G, et al. Antibodies to endothelial cells in systemic lupus erythematosus: a potential marker for nephritis and vasculitis. Clin Exp Immunol 1991; 85: 254-61.

25 Savage C O S, Pottinger B E, Gaskin G, Lockwood C M Pusey C D. Pearson J D. Vascular damage in Wegener's granulomatosis and microscopic polyarteritis: presence of
antiendothelial cell antibodies and their relation to antiendothelial cell antibodies and their relation to antineutrophil cyto.

26 Izui S, Lambert P H, Miescher P A. In vitro demonstration of a particular affinity of glomerular basement membrane and collagen for DNA. A possible basis for a local formation of DNA-anti-DNA complexes in systemic lupus erythematosus. $\Im$ Exp Med 1976; 144: 428-33.

27 Chan T M, Frampton G, Cameron J S. Identification of DNA-binding proteins on human umbilical vein endothelial cell plasma membrane. Clin Exp Immunol 1993; 91: 110-4.

28 Shibata S, Sasaki T, Harpel P, Fillit H. Autoantibodies to vascular heparan sulfate proteoglycan in systemic lupus erythematosus react with endothelial cells and inhibit the formation of thrombin-antithrombin III complexes. Clin Immunol Immunopathol 1994; 70: 114-23.

29 Tokunaga O, Watanabe T. Atherosclerosis and endothelium. Part 1. A simple method of endothelial cell culture from human atherosclerotic aorta. Acta Pathol Ypn 1987; 37: 527-36.

30 Tokunaga $\mathrm{O}$, Fan J, Watanabe T. Atherosclerosis- and agerelated multinucleated variant endothelial cells in primary culture from human aorta. Am $\mathcal{F}$ Pathol 1989; 135: 967-76. 